\title{
The Incidence of Blindness Due to Idiopathic Intracranial Hypertension in the UK
}

\author{
J.L. Best ${ }^{1}$, G. Silvestri ${ }^{1,2}$, B.J. Burton ${ }^{3,4}$, B. Foot ${ }^{5}$ and J. Acheson ${ }^{*}, 3,6$ \\ ${ }^{1}$ Royal Hospitals Belfast Health and Social Care Trust, Ireland \\ ${ }^{2}$ Centre for Vision and Vascular Science (CVVS), Queen's University, Belfast, Ireland \\ ${ }^{3}$ Moorfields Eye Hospital NHS Foundation Trust, London, UK \\ ${ }^{4}$ Royal Hospitals Belfast Health and Social Care Trust, Northern Ireland, UK \\ ${ }^{5}$ Queen's University Belfast, Northern Ireland, UK \\ ${ }^{6}$ National Hospital for Neurology and Neurosurgery, University College London Hospitals NHS Foundation Trust, \\ Queen Square, London, UK
}

\begin{abstract}
Purpose: To determine the incidence of blindness secondary to idiopathic intracranial hypertension (IIH) in the United Kingdom.

Methods: New cases of blindness occurring secondary to IIH were identified prospectively through the British Ophthalmological Surveillance Unit (BOSU) from October 2005 to November 2006. Only idiopathic cases of intracranial hypertension and those meeting the World Health Organisation`s definition of blindness were included. Cases that were already blind or had already been blind registered before the study period were excluded.

Results: There were 24 new cases of registerable blindness secondary to IIH reported during the 12 month period. Questionnaires were completed for 19 cases. Of these 19 cases, 3 were not truly idiopathic and 3 cases did not fulfil the strict criteria for blindness. One case was a duplicate report. There were 12 definite cases of blindness secondary to IIH giving a UK incidence of blindness secondary to IIH of 0.6-2\% (assuming a UK population of 63.2 million and an incidence of IIH of 1-3/100,000). If the 5 cases reported as blind but without a completed questionnaire are assumed to be true cases then the incidence of blindness would be $1-3 \%$.

Conclusions: The results of this study suggest that approximately 1-2\% of new cases of IIH are likely to become blind in a given year. This contrasts with rates of between 4-10\% reported previously in hospital-based studies, but may be a more accurate figure for the population as a whole. Under-ascertainment and improving standards of care may also have contributed to the lower figure than previously reported.
\end{abstract}

Keywords: Blindness, intracranial hypertension, pseudotumour cerebri.

\section{INTRODUCTION}

Idiopathic intracranial hypertension (IIH) (also known as pseudotumour cerebri) is a disorder of unknown aetiology in which there is raised intracranial pressure in the absence of an obvious abnormality on neuroimaging and normal cerebrospinal fluid composition. There have been few epidemiological studies of IIH but these give fairly consistent figures for the incidence of the disease as 1$3 / 100,000 /$ year [1-5]. IIH is much more common in women, particularly obese women of childbearing age, when the incidence is as high as $21 / 100,000 / y e a r$ [2]. The condition also occurs in children, in whom there is no sex predilection and in whom the incidence is reported to be 0.4$2.2 / 100,000 /$ year [6]. Although headache is a major source

*Address correspondence to this author at the Moorfields Eye Hospital, London EC1V 2PD, UK; Tel: +44 207546 2346; Fax: +44 207566 2408;

E-mail: james.acheson@moorfields.nhs.uk of morbidity, the only major complication is visual loss. Data on the incidence of blindness in IIH is very sparse. In one prospective study a rate of bilateral blindness of $4 \%$ was found [4] and two retrospective studies found rates of $6 \%$ [7] and $10 \%$ [8]. These hospital-based studies showed a likely selection bias towards the most severe cases and used variable criteria for definition of blindness. Less severe visual loss including peripheral field constriction, blindspot enlargement and acuity deficits is also quite common, arising in up to $87 \%$ of patients [1,9], but this patient group is outside the criteria for our study. As the disease predominantly affects those of working age and especially women of childbearing age the social and economic implications of major visual loss are substantial. To date no prospective epidemiological study on the incidence of blindness in IIH has been performed in the UK. In this study we have determined the incidence of blindness secondary to IIH in the UK. 


\section{METHODS}

Cases were identified using the established methodology of the British Ophthalmic Surveillance Unit (BOSU [10]. For the 12 months period, October 2005 to November 2006, the yellow BOSU surveillance card, sent to all permanently employed ophthalmologists in the United Kingdom, included a category for new case of blindness secondary to IIH. Recipient ophthalmologists of this card were asked to return it indicating whether they had seen a new case of blindness secondary to IIH in the preceding month. Cases were defined as any patient with true IIH who became eligible to be registered blind during the 12 month study period. Cases that had already become blind prior to the period of the study were excluded. The World Health Organisation (WHO) definition of blindness "a visual acuity of $3 / 60$ or less in the best corrected eye or a central visual field of less than $20^{\circ}$ in the better eye" was used to avoid ambiguity. To avoid the reporting of cases of raised intracranial pressure secondary to known causes the modified Dandy criteria (Table 1) were used to define true IIH cases. Following the notification of a positive case to BOSU, the reporting ophthalmologist was sent an incident questionnaire by the study investigator. Information requested included general details such as the patient's age, gender, ethnic status, weight and height; visual details including date when recorded as blind, Snellen visual acuity, extent of visual field defect (a tick box of choices was used to simplify the reporting of these and if possible the reporting ophthalmologist was asked to attach a copy of the visual fields, with patient details removed, along with the returned questionnaire), the presence of any ocular comorbidity and visual acuity on first presentation along with the date when the patient was seen for the first time. Details on investigations performed including CSF opening pressure on first presentation and neuro-imaging studies were also requested. A tick box requesting details on various management options, including medical and surgical options that were used was also included. If a questionnaire was not returned at least 2 reminder letters were sent. The rate of blindness was calculated using a UK population of 63.2 million in 2011 [11] and an overall incidence of IIH of 13/100,000 [1-4] (ie. An estimated incidence of 630 - 1890 new cases of IIH per year).

Table 1. Modified Dandy Criteria for IIH

\begin{tabular}{|ll|}
\hline 1. & Signs and symptoms of raised intracranial pressure. \\
\hline 2. & $\begin{array}{l}\text { Absence of localising findings on neurological examination (except } \\
\text { sixth nerve palsies or rarely other false localising signs.) }\end{array}$ \\
\hline 3. & $\begin{array}{l}\text { Normal neuroimaging with no evidence of venous sinus obstruction. } \\
\text { (empy sella and dilated optic nerve sheaths are acceptable.) }\end{array}$ \\
\hline 4. & A CSF opening pressure greater than $250 \mathrm{~mm} \mathrm{H2O.}$ \\
\hline 5. & Normal CSF constituents. \\
\hline
\end{tabular}

\section{RESULTS}

During the 12 month surveillance 24 new cases of blindness secondary to IIH were reported through the BOSU reporting card. Nineteen completed questionnaires were returned. Seven cases were excluded. Three of these cases had a history of cerebral venous sinus thrombosis and therefore were not true idiopathic cases of IIH. Three cases did not fulfil the strict definition of blindness set in the inclusion criteria of the study, although all of these cases had severe visual loss. One case was a duplicate report. A notification form only was received in 5 cases, but the initial questionnaire was not returned, and these were considered as 'potential cases'. Therefore a total of 12 eligible questionnaires were received. Assuming an incidence of 598-1794 new cases of IIH in the UK each year (based on a UK population of 59.8 million and an incidence of IIH of 1$3 / 100,000) 0.6-2 \%$ of these cases would be expected to become blind each year. If the 5 'potential cases' reported through BOSU but without a follow-up questionnaire are included then the incidence of blindness in IIH would be rise to $3 \%$.

IIH predominantly affects obese women of childbearing age. In this study 11 of the 12 patients were female and would be classified as clinically obese by BMI. One patient was a 60 year old male who was also clinically obese. Obstructive sleep apnoea might be suspected in this case but was not documented. One of the female patients was a 6 year old child. Two patients received medical treatment alone. Ten patients received medical and surgical interventions. Reported details on each case are summarised in Table $\mathbf{2}$.

\section{DISCUSSION}

Although the Severe Sight Impaired register may be useful for estimating the incidence and prevalence of various blinding diseases, the degree of under-certification may be as high as $64 \%$ for blind and $77 \%$ for partially sighted people [12]. Using the BOSU reporting system we aimed to provide a more accurate incidence figure for blindness in IIH patients.

Fortunately, in the majority of patients with IIH the disease is self-limiting and relatively mild; however varying degrees of visual loss have been reported in up to $87 \%[1,13]$ of patients who have been carefully monitored. Data on the incidence of blindness in IIH is very sparse however two studies estimated blindness to occur in 6-10\% [7,8] of patients with IIH. Using these earlier estimates between 71 and 118 patients who develop IIH within the UK in a given year might be expected to become blind. The results from this prospective national study suggest that approximately 1 $2 \%$ of new cases of IIH would become blind annually. Some degree of under-ascertainment is inevitable, but active population-based surveillance such as the one operated by BOSU has been demonstrated to be effective $[14,15]$ and is widely supported by the UK ophthalmic community. Ascertainment rates of $75-95 \%$ have been recorded in previous BOSU studies. Patients with visual loss due to papilloedema and optic atrophy may show stato-kinetic dissociation on perimetry with greater deficits on static testing than on kinetic. In this study 10 out of 12 patients had kinetic Goldmann testing. A further issue is the rate of nonorganic visual loss and exaggerated visual deficits in this patient population as reported by Ney in 2009 [16]. Although in our study data on optic atrophy was not requested to allow disc-field correlations, we believe that this is not a significant source of bias as in a recently reported series of blind registrations from a clinical neurosciences centre [17], only one patient out of 40 fell into this category. 
Table 2. Clinical Details of 12 Reported Cases of Blindness (World Health Organisation Definition) Due to Idiopathic Intracranial Hypertension

\begin{tabular}{|c|c|c|c|c|c|c|c|c|c|}
\hline Case & Gender & Age (Yrs) & Ethnicity & $\begin{array}{c}\text { Visual Acuity } \\
\text { RE LE }\end{array}$ & $\begin{array}{l}\text { Visual Fields } \\
\text { RE LE }\end{array}$ & $\begin{array}{c}\text { Time from } \\
\text { First Presentation } \\
\text { to Blindness }\end{array}$ & \begin{tabular}{|c|} 
LP Opening \\
Pressure on \\
Presentation
\end{tabular} & $\begin{array}{c}\text { Medical } \\
\text { Management }\end{array}$ & $\begin{array}{c}\text { Surgical } \\
\text { Management }\end{array}$ \\
\hline 2 & female & 6 & White & $<3 / 60<3 / 60$ & Unable to perform $\mathrm{VF}$ & 4 months & $40 \mathrm{~cm} \mathrm{H}_{2} \mathrm{O}$ & Nil & LP shunt \\
\hline 4 & male & 60 & White & NPL NPL & Unable to perform VF & 2 months & $49 \mathrm{~cm} \mathrm{H}_{2} \mathrm{O}$ & $\begin{array}{l}\text { Diamox } \\
\text { frusemide }\end{array}$ & LP shunt $x 1$ \\
\hline 5 & female & 59 & White & $6 / 246 / 24$ & $<20^{\circ}<20^{\circ}$ & 17 years & $28 \mathrm{~cm} \mathrm{H}_{2} \mathrm{O}$ & Diamox & LP shunt $x 1$ \\
\hline 6 & female & 32 & Black African & CF $3 / 60$ & $<20^{\circ}<20^{\circ}$ & 7 years 6 months & $40 \mathrm{~cm} \mathrm{H}_{2} \mathrm{O}$ & Diamox & $\begin{array}{l}\text { Bilateral ONSF } \\
\text { LP shunt x } 1\end{array}$ \\
\hline 8 & female & 25 & Asian & $6 / 186 / 12$ & $<20^{\circ}<20^{\circ}$ & 6 months & $40 \mathrm{~cm} \mathrm{H}_{2} \mathrm{O}$ & Diamox & LP shunt $x 2$ \\
\hline 9 & female & 52 & White & $6 / 246 / 18$ & $<20^{\circ}<20^{\circ}$ & 3 years & $52 \mathrm{~cm} \mathrm{H}_{2} \mathrm{O}$ & Diamox & VP shunt $x 1$ \\
\hline 10 & female & 19 & White & NPL 6/9 & $<20^{\circ}<20^{\circ}$ & 10 years & $29 \mathrm{~cm} \mathrm{H}_{2} \mathrm{O}$ & $\begin{array}{l}\text { Diamox } \\
\text { frusemide }\end{array}$ & LP shunt $x 2$ \\
\hline 11 & female & 46 & White & $6 / 606 / 9$ & $<20^{\circ}<20^{\circ}$ & 7 months & $51 \mathrm{~cm} \mathrm{H}_{2} \mathrm{O}$ & Diamox & Nil \\
\hline 12 & female & 38 & Black Carribean & $6 / 24 \mathrm{HM}$ & $<20^{\circ}<20^{\circ}$ & 5 months & $40 \mathrm{~cm} \mathrm{H}_{2} \mathrm{O}$ & $\begin{array}{c}\text { Weight loss } \\
\text { Multiple LPs }\end{array}$ & Right ONSF \\
\hline
\end{tabular}

There have been numerous case reports in the literature of potential associations between IIH and many different medical conditions, however two case-control studies [18,19] have shown female sex, reproductive age, obesity and recent weight gain to be the only statistically significant risk factors. In this study 11 patients were female and all 12 patients with completed questionnaires were clinically obese. Curry et al. have published data [20] suggesting that the incidence of CSF shunting for IIH is rising at about the same relative rate as morbid obesity [21]. It is reasonable to assume that the incidence of IIH may be expected to increase in line with the currently predicted obesity epidemic, thus adding to the rate of avoidable visual loss in young people.

Whilst there is no acceptable level of visual loss it is widely agreed that surgical intervention by cerebro-spinal fluid diversion surgery (either a shunting procedure or optic nerve sheath fenestration) should be performed before visual acuity and visual fields are severely compromised or atrophy has supervened. Despite the use of medical and surgical interventions visual loss can occasionally continue relentlessly and further research is needed to determine optimal management in these cases. It is noteworthy that 10 patients in this series had had both medical and surgical interventions, but still showed a very adverse clinical outcome. Delay in presentation, diagnosis and management may also be significant risk factors for blindness.

\section{CONFLICT OF INTEREST}

The authors confirm that this article content has no conflict of interest.

\section{ACKNOWLEDGEMENTS}

The British Ophthalmological Surveillance Unit is based at the Royal College of Ophthalmologists at 17 Cornwall Terrace, London, NW1 4QW and receives an annual grant from the British Eye Research Foundation operating as Fight for Sight, a company limited by guarantee registered in England (Company Number: 0555503) and a charity registered in England by the Charity Commission for England and Wales (RegisteredCharity Number: 1111438) whose registered office is at 5th Floor, 9-13 Fenchurch Buildings, Fenchurch Street, London EC3M 5HR. One author, BF, is employed as research co-ordinator by BOSU.

\section{REFERENCES}

[1] Radhakrishnan K, Thacker AK, Bohlaga NH, Maloo JC, Gerryo SE. Epidemiology of idiopathic intracranial hypertension: a prospective and case control study. J Neurol Sci 1993; 116: 18-28.

[2] Durcan FJ, Corbett JJ, Wall M. The incidence of pseudotumor cerebri: population studies in Iowa and Louisiana. Arch Neurol 1988; 45: 875-7.

[3] Radhakrishnan K, Ahlskog JE, Cross SA, Kurland LT, O`Fallon WM. Idiopathic intracranial hypertension (pseudotumor cerebri): descriptive epidemiology in Rochester, Minn, 1976 to 1990. Arch Neurol 1993; 50: 78-80.

[4] Wall M, George D. Idiopathic intracranial hypertension: a prospective study of 50 patients. Brain 1991; 114: 155-80.

[5] Raoff N, Sharrack B, Pepper IM, Hickman SJ. The incidence of idiopathic intracranial hypertension in Sheffield. Eur J Neurol 2011; 18(10): 1266-8.

[6] Rangwala LM, Liu GT. Pediatric idiopathic intracranial hypertension. Surv Ophthal 2007; 52(6): 507-617.

[7] Orcutt JC, Page NGR, Sanders MD. Factors affecting visual loss in benign intracranial hypertension. Ophthalmology1984; 91: 130312. 
[8] Corbett JJ, Savino PJ, Thompson HS. Visual loss in pseudotumor cerebr: follow- up of 57 patients from five to 41 years and a profile of 14 patients with permanent severe visual loss. Arch Neurol 1982; 39: 461-74.

[9] Rowe FJ, Sarkies NJ. Assessment of visual function in idiopathic intracranial hypertension: a prospective study. Eye 1998; 12: 111-8.

[10] Foot BG, Stanford MR, Rahi J, Thompson JR. The British Ophthalmological Surveillance Unit: an evaluation of the first 3 years. Eye 2003; 17: 9-15

[11] Office for National Statistics. UK Population Estimate Revealed. Available at: http://www.ons.gov.uk [Accessed: $17^{\text {th }}$ Dec 2012].

[12] Evans JR, Wormald RP. Epidemiological function of BD8 certification. Eye 1993; 7(1): 172-9.

[13] Ireland B, Corbett JJ, Wallace RB. The search for causes of idiopathic intracranial hypertension: A preliminary case-control study. Arch Neurol 1990; 47: 315-20.

[14] Thacker SB, Redmond S, Berkelman RL. A controlled trial of disease surveillance strategies. Am J Prev Med 1986; 2: 345-50.

[15] Vogt RL, La Rue D, Klauke DN, Jillison DA. Comparison of an active and passive surveillance system of primary care providers for hepatitis, measles, rubella and salmonellosis in Vermont. Am J Public Health 1983; 73: 795-7.

[16] Ney JJ, Volpe NJ, Liu GT, et al. Functional visual loss in idiopathic intracranial hypertension. Ophthalmology 2009; 116(9): 1808-13.

[17] Patel L, Acheson J. Blind and partially-sighted registrations in the Neuro-Ophthalmology clinic: an audit of causes and additional disabilities. Neuroophthalmology 2012; 36 (S1): 1-65.

[18] Giuseffi V, Wall M, Siegel PZ, Rojas PB. Symptoms and disease associations in idiopathic intracranial hypertension (pseudotumor cerebri): a case control study. Neurology 1991; 41 (2(pt 1)): 23944.

[19] Ireland B, Corbett JJ, Wallace RB. The search for causes of idiopathic intracranial hypertension: a preliminary case-control study. Arch Neurol 1990; 47: 315-20.

[20] Curry WT Jr, Butler WE, Barker FG. Rapidly rising incidence of cerebrospinal fluid shunting procedures for idiopathic intracranial hypertension in the United States, 1988-2002. Neurosurgery 2005; 57(1): 97-108.

[21] Gortmaker SL, Swinburn B, Levy D, et al. Changing the future of obesity: science, policy, action. Lancet 2011; 378(9793): 838-47. 